\title{
High efficiency switched boost inverter with integrated closed loop control for photovoltaic based applications
}

\author{
Sushma H R1, Harsha Anantwar ${ }^{2}$ \\ B.E, M.Tech, EEE Department, Dayananda Sagar College of Engineering, Bangalore, India ${ }^{1}$ \\ Assistant Professor, EEE Department, Dayananda Sagar College of Engineering, Bangalore, India ${ }^{2}$
}

\begin{abstract}
In order to supply the power from photovoltaic system or solar panel at a low voltage to a grid at high voltage, a power electronic converter is required which must be capable of both voltage boosting and inversion. Newly introduced Switched boost inverter is a single stage dc-ac power converter whose output voltage can be either greater or less than its input dc voltage and is capable of achieving both these objectives. This converter can supply both ac and dc loads simultaneously which makes it suitable for micro grid applications. This converter allows the switching shoot through switching state of the inverter legs for boosting the input voltage and compensates the dead time effects and avoid the risk of damaging the converter. In this paper principle of operation of switched boost inverter is explained in detail. Also pulse width modulation control strategy for switched boost inverter is formulated and implemented using simple analog circuit.
\end{abstract}

Index Terms: Switched Boost Inverter (SBI), pulse width modulation (PWM), Photovoltaic source (PV).

\section{INTRODUCTION}

Distributed Power Generation Systems (DPGS) based on the renewable energy sources such as solar PV panels, wind, fuel cell, etc. are emission free, more reliable, efficient, and can generate better quality power compared to the conventional centralized power generating systems [1]-[5]. Moreover, as they can be located very close to the consumer load centre, there is no requirement of long transmission and distribution networks. In a general distributed power generation system for residential power applications., the variable dc voltage produced by the renewable energy source (solar panel or fuel cell) is first converted into a constant dc bus voltage using a power electronic converter [1]- [2]. This DC bus can be directly used to supply the dc loads in the system such as LED and fluorescent lamps, computers, and dc motor based water pumps and fans.

Unlike the traditional VSI, the ac output voltage of SBI can be either higher or lower than the available dc input voltage. Also, as the SBI is tolerant to the shoot-through in the inverter phase legs, it exhibits better EMI noise immunity and doesn't require dead-time to protect the converter switches [4]-[5]. Thus, the use of SBI increases the reliability of the overall system. It can supply both ac and dc loads simultaneously from a single dc input source. These features cannot be obtained in the traditional inverters and they are more advantageous for power applications [8].

The proposed Switched Boost Inverter uses PWM control technique for the power applications. This inverter has some special features and is as follows: $\mathrm{SBI}$ is a single or one stage power converter which converts dc voltage into ac voltage and supplies both ac and dc loads simultaneously from a single dc input. So it can perform the functions of both de to dc converter for solar panel and dc to ac converter in a single stage. Hence it reduces the size and cost of overall system.

SBI can produce an ac output voltage, which is either greater or less than the available dc input[5] and thereby a wide range of output voltage for a given dc input voltage can be obtained, it is one of the advantage of SBI . SBI has a better Electro Magnetic Interference (EMI) noise immunity as compared to the traditional Voltage Source Inverter (VSI), because shoot-through event due to EMI noise will not damage the switches of SBI and thereby it eliminates the requirement of converter protection circuits and helps in realization of compact design of the converter circuit. As SBI allows shoot-through event, it does not has the requirement of dead time circuit and thereby it eliminates the complex dead time compensation technologies, which are required to minimize or compensate the waveform distortion caused by the dead time of VSI. The proposed topology switched boost inverter for renewable energy based for residential power applications has high reliability and these makes the system more efficient for many applications. The proposed topology has a PV source(Power produced by the PV panel has to be processed before delivering to the load and boost converter is a basic dc- dc converter i.e often used for that purpose).

On looking into short comings of this topology a modified circuit configuration is developed and its performance is verified using matlab/simulink.

A developed SBI fed with photovoltaic source along with integrated closed loop control is proposed with features like, 
- Separate closed loop for converter and inverter are absent.

- Integrated closed loop control. Both closed loop are combined such a way that a single control loop produces the pulses of both inverter and converter.

- Output voltage is maintained same

- Input dc voltage is reduced

- $\quad$ PV panel is also included as the input voltage range is between the photovoltaic generation limits.

- Low device stress.

- Reduced switching losses with high efficiency.

\section{PROPOSED TOPOLOGY}

Switched boost inverter is a single input, two output power converter. Fig. 1 shows the schematic arrangement of SBI supplied by PV source. SBI is a buck- boost type of DC-AC converter similar to the classical ZSI. The proposed topology consists of a simple boost converter interposed between voltage source and inverter bridge. The major components are an active switch (S), a diode (D), one inductor (L), and one capacitor (C) interposed between voltage source $\mathrm{Vs}$ and the inverter bridge. These components form a boost network of SBI. A low pass filter is used at the output side of the inverter bridge in order to filter the switching frequency components in the bridge output. Bridge output, $\mathrm{L}_{\mathrm{f}}$, and $\mathrm{C}_{\mathrm{f}}$ forms the filter circuit.

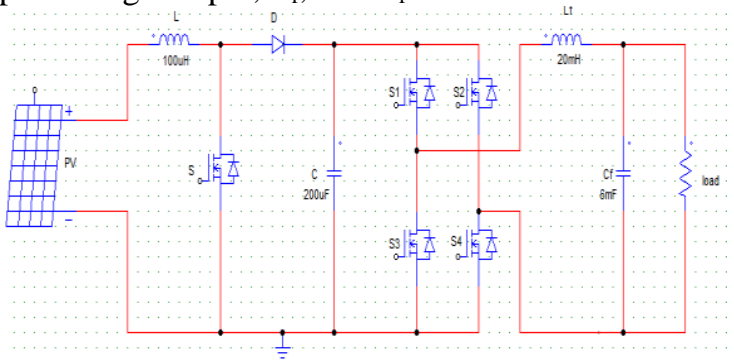

Figure 1: circuit diagram of SBI

The circuit of SBI makes use of MOSFET switches S, S1, $\mathrm{S} 2, \mathrm{~S} 3$ and S4. In order to study the steady state characteristics of SBI, consider $T_{s}$ as a switching time and $\mathrm{D}$ be the duty cycle. The steady state operation of SBI are described below. The converter operates in two states shoot through and non shoot through states.

Initially, inverter is assumed to be in shoot through state for duration D. $T_{\mathrm{s}}$ during switching period $\mathrm{T}_{\mathrm{s}}$. The switch $\mathrm{S}$ is turned on during this interval. Inverter Bridge is shorted. Fig.2a shows the equivalent circuit diagram.

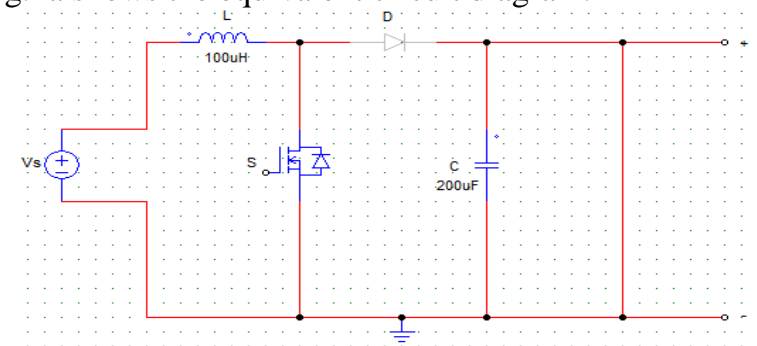

Figure 1a: equivalent circuit of the SBI during DTs
When switch is on current in the boost inductor increases linearly and diode $\mathrm{D}$ is reverse biased and inverter bridge acts as a short circuited. Capacitor $\mathrm{C}$ charges the inductor $\mathrm{L}$ through $\mathrm{S}$ and inverter bridge. During this interval inductor current is equal to capacitor discharging current.

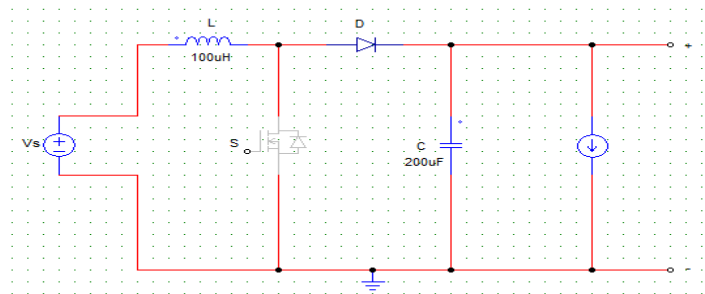

Figure 1b: equivalent circuit of the SBI during (1-D)Ts

For the remaining duration i.e, (1-D) $\mathrm{T}_{\mathrm{s}}$ inverter will be in non shoot through state. Switch $\mathrm{S}$ is turned off . During this interval Inverter Bridge is represented by a current source. Energy stored in inductor is released through the diode D means source and inductor together supply power to the inverter and the capacitor through diode D. Fig.2b shows the equivalent diagram.

The duty cycle $\mathrm{D}$ can be defined by the equation below

$\frac{\mathrm{v}_{\mathrm{O}}}{\mathrm{v}_{\mathrm{s}}}=\frac{1}{1-\mathrm{D}}$

In the proposed circuit, zinductor current is given by the equation below

$\mathrm{I}_{\mathrm{L}}=\frac{\mathrm{Vi}}{(1-\mathrm{D})^{2} * \mathrm{R}} \ldots \ldots \ldots \ldots \ldots \ldots \ldots \ldots$

Ripple voltage is given by the equation below

$\frac{\Delta \mathrm{Vo}}{\mathrm{Vo}}=\frac{\mathrm{DTs}}{\mathrm{RC}}$

Capacitance is given by the equation

$\mathrm{C}=\frac{\mathrm{DTs}}{\mathrm{R} *\left(\frac{\Delta \mathrm{Vo}}{\mathrm{Vo}}\right)}$

\section{PWM CONTROL OF SWITCHED BOOST INVERTER}

A modified PWM control strategy is used for the proposed SBI based on the traditional sine-triangle PWM. In this scheme the switching losses have been reduced and here the switching frequency of switch $\mathrm{S}$ is high and it is kept constant[5]. $\mathrm{V}_{\text {tri }}(\mathrm{t})$ is a high frequency triangular carrier signal of amplitude $V_{p}$ and having frequency $f_{s} . V_{m}(t)$ and $-V_{m}(t)$ are the sinusoidal modulation signals of amplitude $M . V_{p}$ (M is the modulation index) and having frequency $f_{o} . f_{s}$ should be chosen such that, it must be greater than the fo. Because of this reason $V_{m}(t)$ is nearly constant during a switching cycle[5].

Signals ST1 and ST2 are generated by comparing $\mathrm{V}_{\text {tri }}(\mathrm{t})$ with constant voltages, Vst and -Vst respectively. The gate signals for switches $\mathrm{S} 1(\mathrm{GS} 1)$ and S2(GS2) are generated by comparing $\mathrm{Vm}(\mathrm{t})$ and $-\mathrm{Vm}(\mathrm{t})$ with $\mathrm{Vtri}(\mathrm{t})$. similarly gate control signals for switch S3 (GS3) is generated by NAND operation on $\mathrm{S}_{\mathrm{a}}(\mathrm{ST} 1)$ and Gs2 and for switch $\mathrm{S} 4(\mathrm{Gs} 4)$ is generated by NAND operation on $\mathrm{S}_{\mathrm{a}}(\mathrm{ST} 1)$ and $\mathrm{S}_{\mathrm{b}}(\mathrm{ST} 2)$ [5]. 
Inverter input voltage will be high when Gs is low and vice-versa.

The purpose of these two signals i.e $S_{a}$ and $S_{b}$ is to insert the required shoot through interval DTs in the gate signals of the inverter bridge.

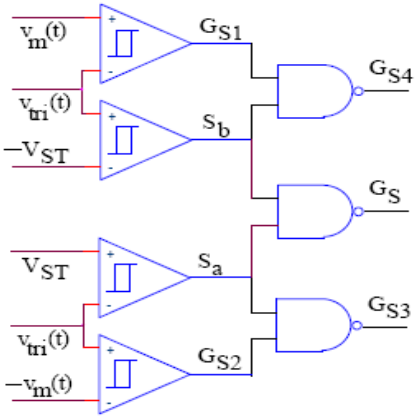

Fig 2(a): Schematic of PWM control circuit

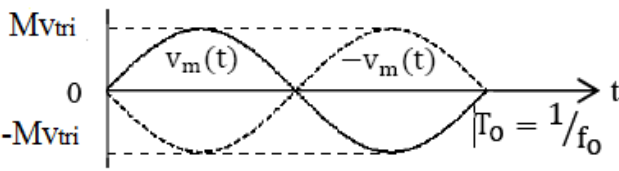

Fig 2 (b): Sinusoidal modulation signals $v_{m}(t)$ and $-v_{m}(t)$

Now gate control signals for switches S3, S4 and S can be obtained by using logical expressions given as follows:

$\mathrm{GS} 3=\mathrm{GS} 2+\mathrm{ST} 1$;

GS4=GS1+ST2;

$\mathrm{GS}=\mathrm{ST} 1+\mathrm{ST} 2$

Similarly for switches S1, S2 and S, logical expressions are GS1=GS4+ST1;

$\mathrm{GS} 2=\mathrm{GS} 3+\mathrm{ST} 2$;

$\mathrm{GS}=\mathrm{ST} 1+\mathrm{ST} 2$

With this PWM control technique, the shoot through state of the inverter bridge will have no effect on the harmonic spectrum of the inverter's output voltage[5], if the sum of duty ratio (D) and the modulation index (M) is less than or equal to unity, i.e

$\mathrm{M}+\mathrm{D} \leq 1$

\section{RESULTS AND DISCUSSION}

\section{A. Circuit Arrangement:}

The figure below shows the circuit arrangement of fig 5 in MATLAB simulation package. The performance of the SBI circuit is verified for the various input voltage and the ac output of $230 \mathrm{v}$ is obtained.

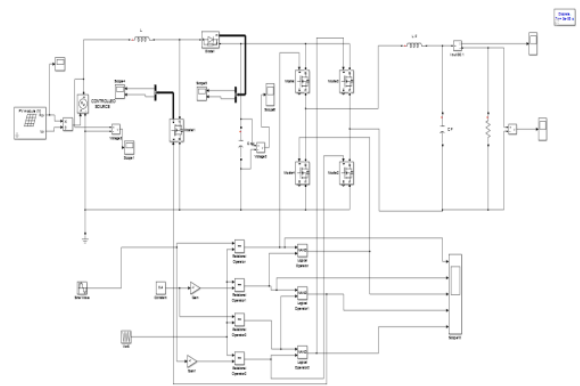

Figure 3: Circuit Arrangement in MATLAB Simulation Package

\section{B. Circuit Specifications:}

The specific values used in the simulation as tabulated as below in table 2 ,

\begin{tabular}{|c|c|}
\hline Parameters & Values \\
\hline $\mathrm{L}$ & $100 \mu \mathrm{H}$ \\
\hline $\mathrm{C}$ & $200 \mu \mathrm{F}$ \\
\hline $\mathrm{Lf}$ & $20 \mathrm{mH}$ \\
\hline $\mathrm{Cf}$ & $6 \mathrm{mF}$ \\
\hline $\mathrm{R}$ & $212 \Omega$ \\
\hline Fs & $100 \mathrm{KHz}$ \\
\hline Input voltage & $37 \mathrm{~V}$ \\
\hline Output voltage & $230 \mathrm{~V}$ \\
\hline
\end{tabular}

Table2: specified values used in simulation

\section{Simulation Results:}

The figure 4 shows the simulation results of bridge output voltage, output current, output voltage and output power for input voltage of $37 \mathrm{~V}$ proposed SBI converter is as shown below.

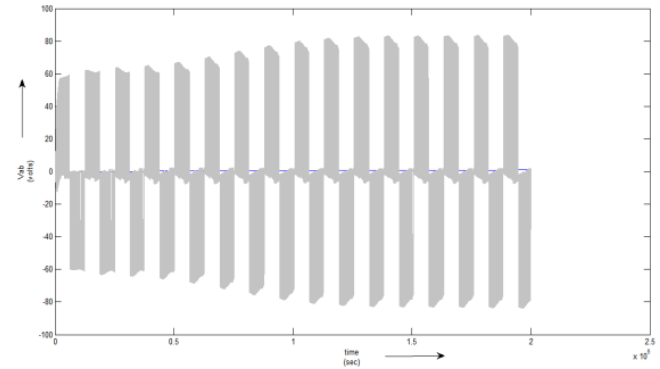

Figure4(a)output voltage of Inverter Bridge in proposed SBI for an input of $37 \mathrm{~V}$

The output voltage of Inverter Bridge of the proposed converter is showed in Fig 4(a). The output of bridge is usually square wave. To make this into a sine wave output, a low-pass LC filter is used on the output side of the inverter. Here Vab is termed as bridge output voltage, Vab is around $64 \mathrm{v}$.

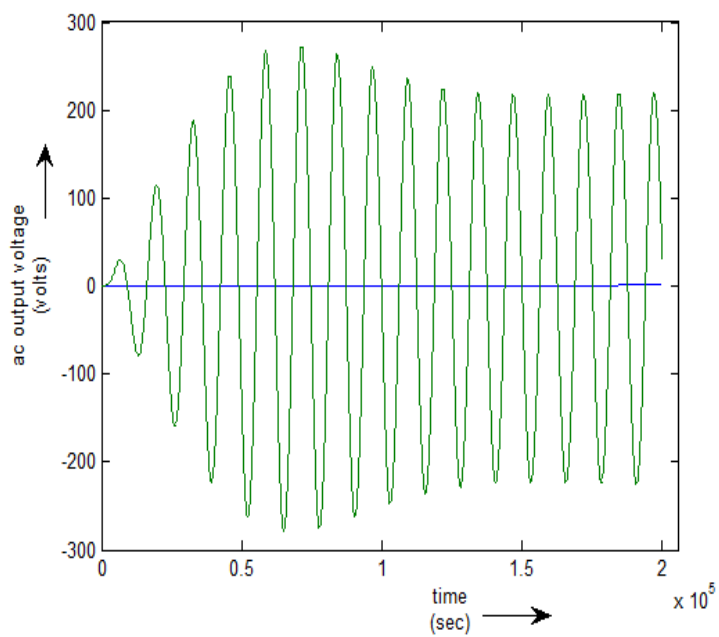

Figure 4(b): output voltage of proposed converter for an input of $37 \mathrm{~V}$

Fig 4(b) shows the inverter output voltage after filtering out the switching frequency components in the output voltage of Inverter Bridge. The output voltage is $230 \mathrm{~V}$. 


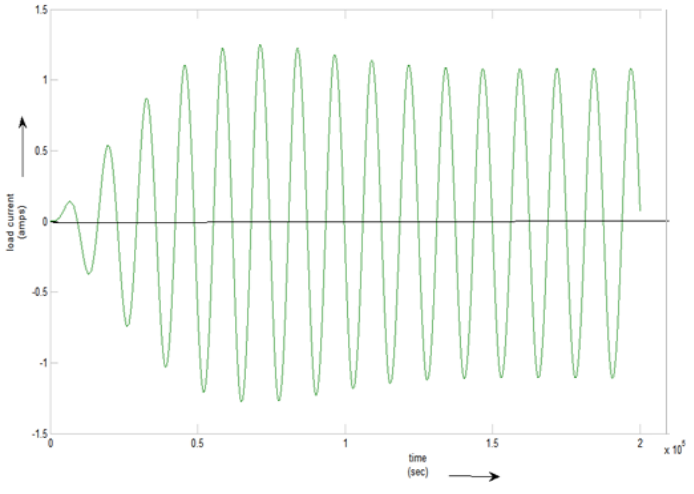

Figure 4(c): output current of the proposed converter for a load of $225 \mathrm{ohm}$

Fig 4(c) shows the output current of the proposed SBI. Proposed converter output current is improved one which is greater than the conventional SBI. Load current is of $1.08 \mathrm{~A}$ for a resistive load of $212 \mathrm{ohms}$.

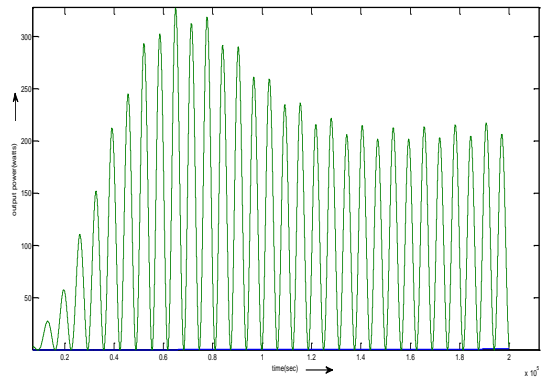

Figure4(c)output power of the SBI

Fig 4(d) shows the power output of the proposed converter. Here we are obtaining improved power range of 200 to 280 watts. In case of conventional range output power range os about 250W. From the Fig 4(d) we can see that power is increased from low value and reaches higher value and becomes constant, it is ac in nature. The efficiency of the converter is measured for the voltage level, the efficiency measured is $95.6 \%$ for the input voltage of $37 \mathrm{~V}$.

\section{CONCLUSION}

An efficient solution for providing distributed PV conversion, an isolated boost converter is proposed. The proposed topology can reduce the switching loss and voltage stress. The proposed inverter is analyzed through the operation mode, and its validity is proven through simulation. This is a hybrid between a conventional CCM boost converter and a resonant half bridge, employing only two active switches. The synthesis of the converter was described along with the circuit operating modes and waveforms. The design process was then defined. The result was simple process, requiring only considering of the resonant period length in selecting a valid converter duty cycle range. The principle advantages of utilizing this topology were as follows:

- High weighted efficiency because of low circulating energy and reduced switching loss.

- Low potential cost due to minimal number of switches and small overall component count.
- Reduced control complexity provides lower auxillary power loss and simpler controller IC

- configurations.

\section{REFERENCES}

[1]. Single phase utility interactive switched boost inverter for renewable energy based residential power applications, IEEE transaction on power electronics 2013.

[2]. Simulation of Single Phase Inverter using PSIM Software for Solar P.V. System give Constant Output Voltage at Different Solar Radiation, International Journal of Emerging Trends in Electrical and Electronics (IJETEE - ISSN: 2320-9569) Vol. 4, Issue. 1, June-2013

[3]. Implementation of a Boost-Buck Converter Based PV Inverter Fed Induction Motor ,Proceedings of National Conference on Emerging Scenario in Power Engineering and Electrical Drives, 7th February 2013

[4]. High Efficient Module of Boost Converter in PV Module, International Journal of Electrical and Computer Engineering (IJECE) Vol.2, No.6, December 2012, pp. 758 781

5]. A PWM Control Strategy for Switched Boost Inverter Ravindranath Adda, Student Member, IEEE, Santanu Mishra, Member, IEEE, and Avinash Joshi Department of Electrical Engineering IEEE transactions on power electronics, November 2011

[6]. Synchronous-Reference-Frame-Based Control of Switched Boost Inverter for Standalone DC Nanogrid Applications Ravindranath Adda, Student Member, IEEE, Olive Ray, Student Member, IEEE, Santanu K. Mishra, Member, IEEE, and Avinash Joshi. IEEE transactions on power electronics, vol. 28, no. 3, march 2013

[7]. Power electronic systems for grid integration of renewable energy source a survey, J.M Carrasco, L.G. Franquelo, IEEE trans.Ind. Electron, vol.53, no.4, and june2006.

[8]. A DSPIC Implementation of a Sliding Mode Strategy for a SEPIC Converter Arivukkannu Ezhilarasi1, Muthiah Ramaswamy SERBIAN JOURNAL OF ELECTRICAL ENGINEERING Vol. 6, No. 2, November 2009,

[9]. Simulation of Single Phase Grid Connected Photo Voltaic System Based On PWM Control Of Switched Boost Inverter For DC Nanogrid Applications, International Journal of Engineering Science Invention, Volume 3 Issue 7\| July $2014 \|$ PP.49-56.

[10]. Energy analysis by NREL(National renewable energy laboratory

[11]. TEXAS Instruments, Digital signal controller (DSC): data Manual [online]. Available: http://www..ti.com/lit/ds/sprs439i.pdf

[12]. TEXAS Instruments, enhanced pulse width modulator (ePWM) Module Reference Guide data Manual [online]. Available: http://www..ti.com/lit/ug/sprug04a.pdf

[13]. Design \& Simulation of PV based Switched Boost Inverter for Grid connected System International Journal of Electrical and Electronics Engineering (IJEEE), ISSN Volume-4, 2013

[14]. Phase locked loop and synchronization methods for grid interfaced converters: an Electrical Review, ISSN 0033-2097, /2011 